\title{
Implementasi FMEA dalam Menganalisis Risiko Kegagalan Proses Produksi Berdasarkan RPN
}

\author{
Raynaldhi Yudha Prasetya*1, Suhermanto Suhermanto ${ }^{2}$, dan Muryanto Muryanto ${ }^{3}$ \\ 1,2,3 Teknik Pemeliharaan Mesin Otomasi, Akademi Komunitas Toyota Indonesia, Jl. Trans Heksa No.01 Desa \\ Margamulya, Kecamatan Telukjambe, Kabupaten Karawang, 41361, Indonesia \\ Email: $\underline{\text { raynaldhi@akti.ac.id }}{ }^{1}, \underline{\text { suhermanto@ akti.ac.id }}^{2}, \underline{\text { muryanto@akti.ac.id }}^{3}$
}

\begin{abstract}
Abstrak
Pengendalian kualitas merupakan hal yang penting untuk mempertahankan posisi perusahaan di mata konsumen. Pada saat ini permasalahan yang terjadi pada perusahaan masih di luar dari ketentuan batas pengendalian proses produksi. Diketahui angka persentase kegagalan pada proses produksi perusahaan sebesar 14\%. Sehingga perusahaan harus segera melakukan perbaikan agar tidak terjadi waste yang merugikan. Maka dengan adanya pengendalian kualitas secara baik dan benar akan diperoleh produk yang dapat memenuhi kebutuhan konsumen. Salah satu alat pemecahan masalah di atas adalah menggunakan metode Failure Modes and Effects Analysis (FMEA). Penggunaan FMEA mampu mengidentifikasi risiko kegagalan yang terjadi selama proses produksi di TL - 5. Tujuan penelitian ini adalah menganalisis moda kegagalan yang menyebabkan terjadi permasalahan, yaitu dengan menggunakan metode FMEA yang berdasarkan nilai Risk Priority Number (RPN). Hasil dari penelitian memberikan usulan perbaikan untuk pengendalian proses produksi selanjutnya. Berdasarkan pengolahan dengan metode FMEA dapat diketahui hasil dari penelitian, terdapat 7 moda kegagalan yang perlu diberikan usulan/tindakan.
\end{abstract}

Kata kunci: Quality Control, Failure Modes and Effect Analysis, Risk Priority Number

\begin{abstract}
Quality control is important to maintain the company's position in the eyes of consumers. At present the problems that occur in the company are still outside the provisions of the production process control limit. It is known that the percentage of failure in the company's production process is $14 \%$. So the company must immediately make improvements so that the disadvantaged waste is detrimental. So with quality control properly and correctly will be obtained by products that can meet consumer needs. One of the problem solving tools above is using the Failure Modes and Effects Analysis (FMEA) method. That the use of FMEA is able to identify the risk of failure that occurs during the production process at TL - 5. The purpose of this study is to analyze the failure mode that causes problems, namely by using the FMEA method based on the value of risk priority number (RPN). The results of the study will provide a proposed improvement for the next production process control. Based on processing with the FMEA method can be known the results of the study, there are 7 modes of failure that need to be given proposals/actions.
\end{abstract}

Keywords: Quality Control, Failure Modes and Effect Analysis, Risk Priority Number

\section{Pendahuluan}

Dalam era kompetisi global saat ini terdapat persaingan antar perusahaan agar dapat meningkatkan keuntungan dan dapat survive dalam kompetisi. Perusahaan tentu selalu berupaya agar dapat memenangkan persaingan di dunia industri (Handoko, 1984). Kepuasan konsumen merupakan faktor penting yang menentukan persaingan perusahaan dalam era kompetisi saat ini. Pengendalian kualitas akan membantu industri untuk mengurangi biaya dan meningkatkan penjualan (Purnomo, 2004), tentunya akan meningkatkan keuntungan perusahaan. Pengendalian kualitas secara terus-menerus adalah hal yang sangat diperlukan agar dapat bersaing pada industri (Kholil \& Prasetyo, 2017).

Pada saat ini dunia industri berkembang pesat, mengakibatkan beragam produk dihasilkan.
Keberagaman produk tersebut memaksa produsen untuk terus meningkatkan kualitas produk yang dihasilkan sesuai dengan keinginan konsumen (Hakim, 2006; Wisnu, 2013). Akan tetapi masih banyak juga pelaku industri yang kurang memperhatikan kualitas produk (proses produksinya). Produk yang tidak sesuai dari standar perusahaan adalah sumber utama pemborosan (Ariani, 2004). Tidak sedikit perusahaan menghadapi masalah serius karena produk tidak sesuai yang menimbulkan klaim dari konsumen (Besterfield, 1998). Jika produk tidak sesuai lolos kepada konsumen dan kemudian menimbulkan kerugian, maka perusahaan harus mengganti kerugian yang dialami konsumen. Salah satu dampak negatif yang diakibatkan adalah runtuhnya posisi perusahaan di mata konsumen (Gasperz, 1998). Jika kondisi demikian tidak diatasi dengan segera,

\footnotetext{
${ }^{*}$ Penulis korespondensi
} 
perusahaan akan kehilangan konsumen potensial (Feingenbaum, 1992). Dengan adanya pengendalian kualitas secara baik dan benar, maka akan diperoleh produk yang dapat memenuhi keinginan konsumen. Salah satu tools yang digunakan untuk membantu pengendalian kualitas adalah menggunakan metode Failure Modes and Effects Analysis (FMEA).

Oleh karena itu pentingnya analisis konsistensi dengan metode FMEA agar dapat diterapkan sesuai dengan kebutuhan dan kondisi perusahaan. Penelitian mengenai penerapan konsistensi penggunaan metode FMEA menghasilkan beberapa modifikasi terhadap penggunaan analisis risiko metode FMEA. Hasil penelitian lain mengenai modifikasi metode FMEA dengan tujuan untuk meningkatkan hasil Risk Priority Number (RPN) untuk mengetahui permasalahan lainnya (Sutrisno \& Lee, 2011). Beberapa modifikasi FMEA yang dilakukan antara lain: Mark A. Moris (2014) melakukan penelitian terhadap menggunaan metode FMEA dengan menggunakan referensi tambahan dari AIAG (Automotive Industry Action Group), DFMEA (Design FMEA) dan PFMEA (Process FMEA) untuk menghasilkan penggunaan FMEA pada ASQ Automotive Division Webinar. Tujuan dari penelitian tersebut untuk menjelaskan tujuan, keuntungan, dan sasaran FMEA. Selain itu penelitian tersebut menyarankan untuk memilih tim yang berkompeten untuk melakukan analisis risiko yang optimal dalam menggunakan, mengembangkan dan memenuhi, melakukan tinjauan, kritik, dan pembaharuan dari metode FMEA yang telah ada. Berdasarkan hal tersebut dapat diatur kegiatan tindak lanjut dan verifikasi dari penerapan serta pengembangan metode FMEA yang sesuai dengan referensi AIAG FMEA (Moris, 2014).

Pemahaman dan penerapan fundamental metode FMEA telah dilakukan oleh Carl S. Carlson, seorang peneliti dari ReliaSoft Corporation. Tujuan penelitian tersebut untuk memberikan penjelasan mengenai konsep dan prosedur penggunaan metode FMEA secara efektif dengan enam faktor pada penerapannya (Carlson, 2014). Penggunaan FMEA dimulai pada tahun 1940-an di Amerika Serikat pada bidang manufaktur. Kini, penggunaan FMEA juga digunakan pada industri perbankan. Bank membutuhkan pengembangan produk yang cepat dengan kualitas terbaik yang dapat meningkatkan kualitas dari loyalitas pelanggan (Gundry, 2014).

FMEA merupakan sebuah metodologi yang digunakan untuk mengevaluasi kegagalan terjadi dalam sebuah sistem, desain, proses, atau pelayanan (service). Identifikasi kegagalan potensial dilakukan dengan cara pemberian nilai atau skor masing-masing moda kegagalan berdasarkan atas tingkat kejadian (occurrence), tingkat keparahan (severity), dan tingkat deteksi (detection) (Stamatis, 1995). Secara umum, terdapat dua tipe FMEA, FMEA desain dan FMEA proses. Pada FMEA desain, pengamatan difokuskan pada desain produk. Sedangkan FMEA proses, pengamatan difokuskan pada kegiatan proses produksi (Yeh \& Hsieh, 2007). Metode yang diterapkan pada penelitian ini adalah FMEA proses, karena pengamatan hanya dilakukan pada kegiatan proses produksi yang sedang berlangsung dan tidak memperhatikan desain produk. Tujuan penerapan metode ini adalah untuk meminimasi kemungkinan terjadi proses produksi yang tidak sesuai.

Berdasarkan paparan yang telah diuraikan, tujuan penelitian ini adalah menganalisis moda kegagalan yang menyebabkan terjadi permasalahan selama proses produksi di TL - 5 dengan menggunakan metode FMEA yang berdasarkan nilai Risk Priority Number (RPN).

\section{Metode Penelitian}

\subsection{Diagram Alur Penelitian dan Pengembangan}

Penelitian ini diawali dengan melakukan identifikasi masalah yang terjadi di perusahaan, dilanjutkan dengan studi literatur dari beberapa penelitian/pengembangan terdahulu. Hal tersebut berguna untuk mencari referensi penelitian dan pengembangan yang dilakukan.

Selanjutnya dilakukan pengambilan data, dengan cara wawancara langsung kepada pihak perusahaan mengenai temuan masalah yang terjadi. Lalu dilanjutkan dengan pengolahan data dengan menggunakan metode failure modes and effect analysis (FMEA) (Montgomery, 2009). Diagram alur penelitian dan pengembangan yang dilakukan seperti pada Gambar 1. di bawah ini. 


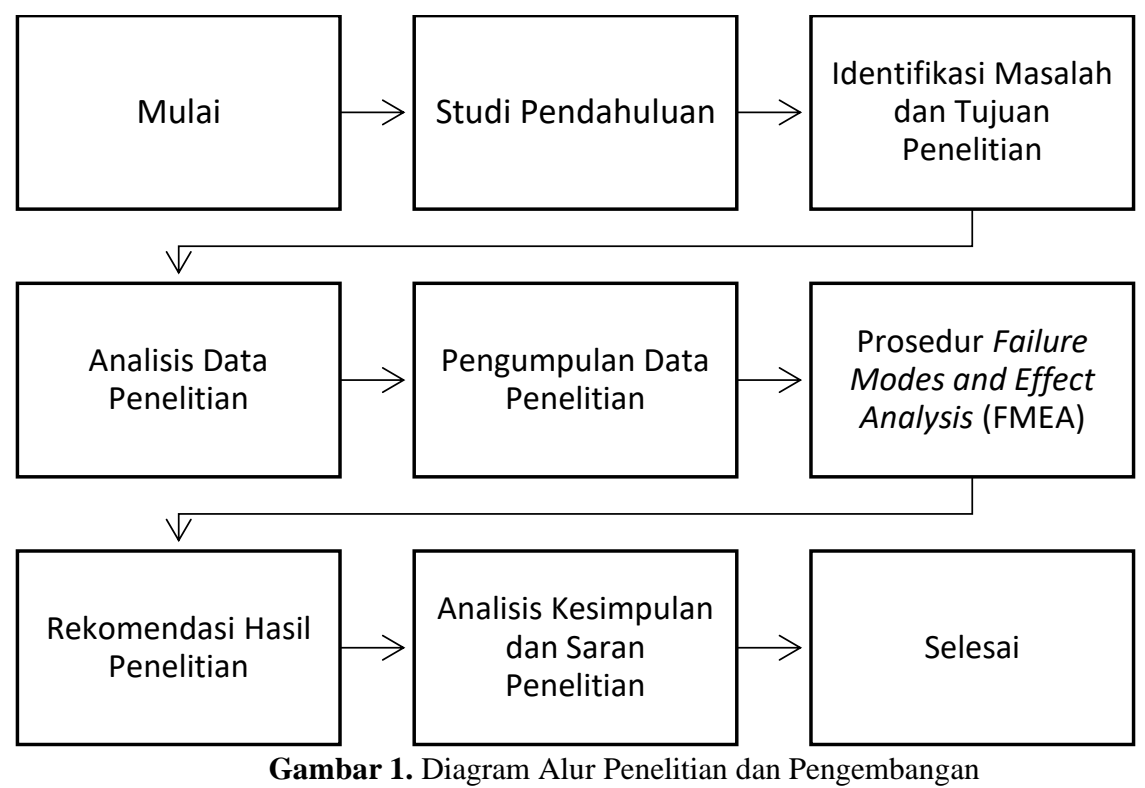

\subsection{Variabel dan Definisi Operasional Penelitian dan Pengembangan}

Setelah dilakukannya identifikasi masalah berdasarkan tujuan penelitian dan pengembangan untuk meningkatkan perbaikan proses produksi di TL - 5 . Produksi yang berlangsung di TL -5 adalah komponenkomponen pada kendaraan mobil. Permasalahan yang umum terjadi adalah load failure (kagagalan berlebih) dan jumper electrical circuit (tersengat arus listrik). Hal ini terjadi karena tidak sesuai dengan standar operasional prosedur (SOP) pekerjaan. Unit analisis dalam objek penelitian dan pengembangan ini adalah TL - 5 .

\subsection{Teknik Pengambilan Sampel}

Teknik pengambilan sampel dalam penelitian ini menggunakaan purposive sampling. Purposive sampling adalah pengambilan sampel dengan cara pertimbangan tertentu. Dengan demikian, mekanisme pengambilan sampel penelitian hanya dilakukan di $\mathrm{TL}-5$ saja.

\subsection{Teknik Analisis Data}

Hasil dari teknik analisis data yang dilakukan dengan metode Failure Modes and Effect Analysis
(FMEA) diketahui terdapat 2 permasalahan utama berdasarkan nilai Risk Priorty Number (RPN).

\subsection{Metode Pencarian dan Pengumpulan Data}

Dalam melakukan metode pencarian dan pengumpulan data, dilakukan studi pustaka untuk mencari referensi sebagai parameter dalam melakukan penelitian ini. Studi pustaka tersebut melalui buku, artikel ilmiah, jurnal, modul/diktat dan lain-lain. Selain itu dilakukan studi lapangan untuk mengetahui kondisi eksisting yang terjadi dalam kegiatan/aktivitas produksi.

\section{Hasil dan Pembahasan}

Penelitian ini dilakukan pada area kerja, bagian proses produksi di TL - 5. Selanjutnya dilakukan wawancara/pengamatan dengan salah satu pekerja. Hal ini sebagai bahan acuan untuk menganalisis permasalahan yang terjadi yaitu TL Load Failure dan Jumper Electrical Circuit. Maka berikut ini merupakan alur sistem kerja yang terjadi permasalahan. Seperti pada Gambar 2. di bawah ini.

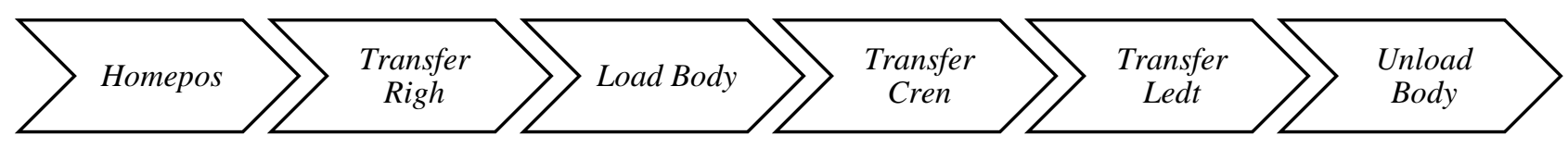

Gambar 2. Alur Sistem Kerja yang Terjadi Permasalahan

Berdasarkan Gambar 2. di atas diketahui alur sistem kerja yang terjadinya permasalahan, yaitu load failure (kagagalan berlebih) dan jumper electrical circuit (tersengat arus listrik). Homepos merupakan area produksi awal sebelum masuk ke bagian area produksi selanjutnya. Ketika pergantian ke area produksi I dikatakan transfer righ. Transfer cren ke area produksi II dan transfer ledt ke area produksi III. Pada masingmasing area produksi memiliki pekerjaan yang berbedabeda, mulai dari pemeriksaan, perakitan dan pemilihan. Permasalahan muncul mendominasi di pertengahan proses produksi, diberikan keterangan load body. 
Sedangkkan unload body adalah proses produksi sesuai dengan standar perusahaan.

Tahapan yang harus dilakukan pada Failure Modes and Effect Analysis sebagai berikut:

1. Menentukan komponen dari sistem/alat yang akan di analisis.

2. Mengidentifikasi moda kegagalan dari proses yang di amati.

3. Mengidentifikasi akibat/potential effect yang ditimbulkan potential failure.

4. Mengidentifikasi penyebab/potential cause dari mode kegagalan yang terjadi pada proses berlangsung.
5. Menetapkan nilai-nilai/dengan cara observasi lapangan dan brainstroming

6. Menentukan nilai risk priorty number (RPN), yaitu nilai yang menunjukkan keseriusan dari potential failure.

Pada kegiatan proses produksi di $\mathrm{TL}-5$, penentuan kegagalan proses produksi dilihat dari kegiatan waktu dan proses produksi.

\subsection{Moda Kegagalan Potensial di TL - 5}

Setelah di lakukan analisis mengenai moda kegagalan potensial di TL -5 . Maka berikut hasil analisis pada Tabel 1.

Tabel 1. Moda Kegagalan Potensial di TL-5

\begin{tabular}{cll}
\hline No. & \multicolumn{1}{c}{ Problem } & \multicolumn{1}{c}{ Failure Mode } \\
\hline 1. & & Operator TL- 5 mengabaikan OEE/QCC \\
2. & TL Load Failure & Operator TL -5 shift real time \\
3. & & Operator TL -5 penggunaan mesin/alat \\
\hline 1. & & Jumper menggunakan kabel \\
2. & Alat/mesin proses produksi \\
3. & Jumper Electrical Circuit & SOP Terabaikan \\
4. & & Minim Identifikasi K3 \\
\hline
\end{tabular}

\subsection{Ranking Risk Priority Number (RPN) untuk Masing-Masing Moda Kegagalan}

Setelah di lakukan analisis mengenai ranking risk priorty number (RPN) untuk masing-masing moda kegagalan. Maka berikut hasil analisis pada Tabel 2.

Tabel 2. Ranking Risk Priorty Number (RPN) untuk Masing-Masing Moda Kegagalan

\begin{tabular}{|c|c|c|c|c|c|c|c|}
\hline Problem & Failure Mode & Cause of Failure & Effect of Failure & $\begin{array}{l}\mathbf{S} \\
\mathbf{e} \\
\mathbf{v}\end{array}$ & $\begin{array}{l}\mathbf{O} \\
\mathbf{c} \\
\mathbf{c} \\
\mathbf{u} \\
\mathbf{r}\end{array}$ & $\begin{array}{c}\mathbf{D} \\
\mathbf{e} \\
\mathbf{f} \\
\mathbf{e} \\
\mathbf{c} \\
\mathbf{t}\end{array}$ & $\begin{array}{l}\mathbf{R} \\
\mathbf{P} \\
\mathbf{N}\end{array}$ \\
\hline \multirow{3}{*}{$\begin{array}{l}\text { TL Load } \\
\text { Failure }\end{array}$} & $\begin{array}{c}\text { Operator TL- } 5 \\
\text { mengabaikan OEE/QCC }\end{array}$ & $\begin{array}{l}\text { Estimasi waktu yang } \\
\text { tidak sesuai dengan } \\
\text { ketentuan perusahaan }\end{array}$ & $\begin{array}{l}\text { Durasi waktu terlalu } \\
\text { lama/tidak sesuai }\end{array}$ & 6 & 7 & 4 & 168 \\
\hline & $\begin{array}{c}\text { Operator } \mathrm{TL}-5 \text { shift real } \\
\text { time }\end{array}$ & $\begin{array}{c}\text { Waktu produksi tidak } \\
\text { ditetapkan }\end{array}$ & $\begin{array}{c}\text { Memakan biaya lebih } \\
\text { untuk produksi }\end{array}$ & 3 & 4 & 3 & 36 \\
\hline & $\begin{array}{c}\text { Operator } \mathrm{TL}-5 \text { salah } \\
\text { penggunaan mesin/alat }\end{array}$ & $\begin{array}{c}\text { Tidak ada kegiatan } \\
\text { pelatihan }\end{array}$ & $\begin{array}{c}\text { Keterlambatan proses } \\
\text { produksi }\end{array}$ & 2 & 1 & 3 & 6 \\
\hline \multirow{4}{*}{$\begin{array}{l}\text { Jumper } \\
\text { Electrical } \\
\text { Circuit }\end{array}$} & $\begin{array}{c}\text { Jumper menggunakan } \\
\text { kabel }\end{array}$ & $\begin{array}{c}\text { Belum ada alat } \\
\text { pendukung }\end{array}$ & $\begin{array}{l}\text { Tersengat dan short } \\
\text { circuit }\end{array}$ & 6 & 7 & 3 & 126 \\
\hline & $\begin{array}{c}\text { Alat/mesin proses } \\
\text { produksi bermasalah }\end{array}$ & $\begin{array}{l}\text { Belum ada alat/mesin } \\
\text { pendukung }\end{array}$ & $\begin{array}{c}\text { Terjadi kecelakaan } \\
\text { kerja }\end{array}$ & 5 & 7 & 3 & 105 \\
\hline & $\begin{array}{c}\text { SOP } \\
\text { Terabaikan } \\
\end{array}$ & $\begin{array}{c}\text { Belum ada SOP khusus } \\
\text { penggunaan }\end{array}$ & $\begin{array}{c}\text { Timbul masalah kerja } \\
\text { bagi pekerja }\end{array}$ & 4 & 5 & 2 & 40 \\
\hline & $\begin{array}{l}\text { Minim Identifikasi } \\
\text { K3 }\end{array}$ & $\begin{array}{c}\text { Tidak ada pelatihan } \\
\text { penggunaan }\end{array}$ & K3 menjadi masalah & 2 & 2 & 1 & 4 \\
\hline
\end{tabular}

Pada Tabel 2. di atas adalah urutan moda kegagalan berdasarkan nilai RPN terbesar. Moda kegagalan dengan nilai RPN terbesar merupakan prioritas untuk dilakukan tindakan korektif.

\subsection{Usulan Perbaikan Berdasarkan Risk Priority Number (RPN)}

Setelah dilakukan analisis mengenai usulan perbaikan berdasarkan risk priorty number (RPN) untuk masing-masing moda kegagalan. Maka berikut hasil analisis pada Tabel 3. 
Tabel 3. Usulan Perbaikan Berdasarkan Risk Priority Number (RPN)

\begin{tabular}{clcl}
\hline $\begin{array}{c}\text { Rangking } \\
\text { RPN }\end{array}$ & \multicolumn{1}{c}{ Moda Kegagalan Potensial } & RPN & \multicolumn{1}{c}{ Usulan Perbaikan } \\
\hline 1 & Waktu produksi berlebih & 168 & Menerapkan program LSS. \\
\hline 2 & Menjumper menggunakan kabel & 126 & Membuat function force on/off LS di screen work \\
\hline 3 & Diperlukan alat/mesin yang sesuai & 105 & Menambahkan program PLC manual work \\
\hline 4 & Belum ada SOP penggunaan & 40 & Merencanakan SOP yang sesuai dengan penggunaan \\
\hline 5 & Tidak ada estimasi waktu produksi & 36 & Membuat batas parameter kegiatan produksi optimal. \\
\hline 6 & Kurangnya keahlian Pekerja & 6 & $\begin{array}{l}\text { Membuat program keterampilan yang sesuai dengan } \\
\text { job descriptionnya. }\end{array}$ \\
\hline 7 & Kurangnya pelatihan & 4 & $\begin{array}{l}\text { Membuat program pelatihan untuk pekerja secara } \\
\text { berkala }\end{array}$ \\
\hline
\end{tabular}

Setelah mendapatkan rangking dari RPN dalam proses FMEA, yaitu memberikan usulan perbaikan terhadap moda kegagalan yang telah di rangking berdasarkan urutan prioritas. Hal tersebut bertujuan untuk memperbaiki pengendalian kualitas pada saat ini di perusahaan. Usulan perbaikan tidak hanya diberikan pada nilai di atas 100 saja, namun untuk semua moda kegagalan yang sudah teridentifikasi tetap diberikan usulan. Hal ini sebagai bahan pertimbangan untuk perusahaan ke depannya.

Pada Tabel 3. di atas telah diketahui urutan prioritasnya, sehingga perlu diberikan usulan perbaikan lebih lanjut. Usulan perbaikan yang dilakukan berdasarkan dari urutan prioritas. Diketahui hasil dari penelitian yang telah dilakukan terdapat 7 moda kegagalan yang perlu diberikan usulan/tindakan. Hasil penelitian dan pengembangan menunjukan terdapat 2 permasalahan utama, yaitu load failure (kagagalan berlebih) dan jumper electrical circuit (tersengat arus listrik).

\section{Kesimpulan}

Berdasarkan hasil akhir dari penelitian dan pengembangan di atas, dapat disimpulkan bahwa metode failure modes and effect analysis (FMEA) dapat untuk menganalisis penyebab terjadinya permasalahan di perusahaan secara berkala. Moda kegagalan yang terjadi di perusahaan untuk TL Failure Mode yaitu Operator TL - 5 mengabaikan OEE/QC, shift real time dan penggunaan mesin/alat. Sedangkan untuk Jumper Electrical Circuit : Jumper menggunakan kabel, alat/mesin proses produksi, SOP terabaikan dan minim identifikasi K3.

Pada kajian lanjutan, studi dapat dilengkapi dengan penggunaan metode lean six sigma melalui pendekatan DMAIC. Hal ini sebagai upaya untuk mendukung perusahaan mengoptimalkan proses dan biaya produksi.

\section{Ucapan Terima Kasih}

Author mengucapkan terima kasih kepada Akademi Komunitas Toyota Indonesia Karawang yang telah memberikan pendanaan penelitian internal. Selain itu juga author mengucapkan terima kasih kepada rekanrekan satu departemen Teknik Pemeliharaan Mesin
Otomasi yang telah banyak membantu dalam pelaksanaan penelitian ini.

\section{Daftar Pustaka}

Ariani, D. W., 2004. Pengendalian Kualitas Statistik. Yogyakarta: Andi Offset.

Besterfield, D. H., 1998. Quality Control. New Jersey: Prentice-Hall Inc..

Carlson, C. S., 2014. Understanding and Applying the Fundamentals of FMEA. 1st penyunt. Tucson, Arizona USA: ReliaSoft Corporation.

Feingenbaum, A. V., 1992. Total Quality Control. Dalam: Kendali Mutu Terpadu. Jakarta: Erlangga, pp. 50-62.

Gasperz, V., 1998. Total Quality Management. Jakarta: Gramedia Pustaka Umum.

Gundry, E., 2014. Failure Mode and Effect Analysis in Banking. 1st penyunt. New York: FIS Consulting Services.

Hakim, A. N., 2006. Manajemen Industri. Yogyakarta: Andi Offset.

Handoko, T. H., 1984. Dasar-Dasar Manajemen Produksi dan Operasi. Yogyakarta: BPFE.

Kholil, M. \& Prasetyo, E. D., 2017. Tinjauan Kualitas pada Aerosol Can 65 X 124 dengan Pendekatan Metode Six Sigma pada Line ABM 3 Departemen Assembly. Jurnal Sinergi, XXI(1), pp. 53-58.

Montgomery, D. C., 2009. Statistical Quality Control: A Modern Introduction. United States: Jhon Wiley and Sons, Inc..

Moris, M. A., 2014. Failure Mode and Effect Analysis based on FMEA 4th Edition. 4th penyunt. New York: $\mathrm{M}$ and $\mathrm{M}$ Consulting.

Purnomo, H., 2004. Pengantar Teknik Industri. Yogyakarta: Graha Ilmu.

Puspitasari, N. B. \& Martanto, A., 2014. Penggunaan FMEA dalam Mengidentifikasi Resiko Kegagalan Proses Produksi Sarung ATM (Alat Tulis Mesin) (Studi Kasus PT. Asaputex Jaya Tegal).J@TI Undip, IX(2), pp. 93-98.

Stamatis, D. H., 1995. Failure Mode and Effect Analysis : FMEA from Theory to Execution. 1st penyunt. Milwaukee: ASQC Quality Press.

Sutrisno, A. \& Lee, T. -R., 2011. Service Reability Assessment Using Failure Mode and Effect 
Analysis (FMEA): Survey and Opportunity Roadmap. International Journal of Engineering, Science and Technology, III(7), pp. 25-38.

Wisnu, A. P., 2013. Quality Control: Panduan Penerapan Teknis. Bekasi: Wishnu AP \& Partners. Yeh, R. H. \& Hsieh, M. H., 2007. Fuzzy Assessment of FMEA for Sewage Plant. Journal of the Cinese Institute of Industrial Engineers, XIV(6), pp. 505512. 